\title{
Drug-induced immune hemolytic anemia associated with albumin-bound paclitaxel
}

\author{
Roby Thomas, MD, and Alexandra Shillingburg, PharmD
}

West Virginia University Healthcare, Morgantown

$\mathrm{D}$ rug-induced immune hemolytic anemia (DIIHA) is rare, with only 1 patient in 1 million affected by the condition. ${ }^{1}$ Garratty identified 125 drugs indicated in DIIHA of which $11 \%$ were antineoplastic agents, and neither paclitaxel nor albumin-bound paclitaxel were included. ${ }^{2}$ In addition, we did not find any reports in our own search of the literature. Taxanes are known to cause anemia as a result of their myelosuppressive effects, but an immune hemolysis is rare. To our knowledge, we present here the first case of DIIHA with nab-paclitaxel.

\section{Case presentation}

A 48-year-old woman with ductal carcinoma of the breast was treated with a resection; 6 cycles of adjuvant docetaxel, doxorubicin, and cyclophosphamide with radiation; 4 cycles of capecitabine; and a simple mastectomy. Her disease progressed and metastasized to the lung. She was started on nab-paclitaxel $260 \mathrm{mg} / \mathrm{m}^{2}$ every 21 days as a first-line metastatic treatment. After 3 cycles, the patient achieved a partial response $(\mathrm{PR})$ and requested pursuing more aggressive treatment. Carboplatin was incorporated at area under the curve $=2$ with $80 \mathrm{mg} / \mathrm{m}^{2}$ of nabpaclitaxel on days 1,8 , and 15 of a 28 -day cycle. The day of her first infusion, her hemoglobin ( $\mathrm{Hgb}$ ) was $11.2 \mathrm{~g} / \mathrm{dL}$ (normal range, 10.4-15.3 g/dL) and her hematocrit (Hct) was 31.3\% (normal range, 36.1\%44.3\%). The patient received a total of 15 cycles, and her $\mathrm{Hgb}$ and Hct remained stable (Hgb, 10.8-12.0 g/dL; Hct, 30.3\%-34\%).

Before the next cycle, the patient's Hgb was 10.6 $\mathrm{g} / \mathrm{dL}$ and treatment was given without incident. Three days later, the patient reported experiencing a severe headache without relief, significant weakness, and shortness of breath. Initial test results showed that her Hgb level was $7.3 \mathrm{mg} / \mathrm{dL}$ and her lactate acid dehydrogenase (LDH) level was 309 U/L (normal range, 140-280 U/L). Repeat Hgb was 7.1 mg/
dL. The patient had no obvious source of bleeding, her iron studies results were normal, and tests for disseminated intravascular coagulation (DIC) were negative. Results from a hemolytic anemia workup were: bilirubin, $2.2 \mathrm{mg} / \mathrm{dL}$ (normal range, $0.3-$ $1.9 \mathrm{mg} / \mathrm{dL}$ ); immature reticulocyte fraction, 0.510 (normal range, $0.11-0.38$ ); reticulocyte count 6.8\% (normal range, $0.5 \%-1.5 \%$ ); absolute reticulocyte count $136 \times 10^{3} \mathrm{u} / \mathrm{L}$ (normal range, 21-94.5 x $10^{3} \mathrm{u} / \mathrm{L}$ ).; and haptoglobin, $<3 \mathrm{mg} / \mathrm{dL}$ (normal range, $41-165 \mathrm{mg} / \mathrm{dL}$ ) which is below the detectable threshold. Direct Coombs test results were positive for polyspecific antiglobulin, immunoglobulin $\mathrm{G}(\mathrm{Ig} G)$ specific, and C3 specific. These results suggest an autoimmune hemolytic process. The decision was made to discontinue carboplatin, and treatment continued with nab-paclitaxel alone. Prior to her next treatment, the patient's Hgb was $11.6 \mathrm{mg} /$ $\mathrm{dL}$ and her LDH was $192 \mathrm{U} / \mathrm{L}$. Five days later, her $\mathrm{Hgb}$ was $6.9 \mathrm{mg} / \mathrm{dL}$ and her LDH was $325 \mathrm{U} / \mathrm{L}$, at which time she received a transfusion and remained stable. Hemolysis labs were not repeated at that time, but because of the temporal relationship of nab-paclitaxel administration, it was determined to be the cause of her DIIHA. The patient had no evidence of either DIC or viral illness and was not rechallenged with nab-paclitaxel.

\section{Discussion}

DIIHA has been discussed in medical literature since 1953, and has occurred in over 100 medications. ${ }^{4}$ The absolute incidence of DIIHA is rare, but can be a serious complication leading to fatality. ${ }^{3}$

There are 2 types of drug-related antibodies. Drug-independent antibodies can be detected in vitro without any drug, meaning autoantibodies were produced against the red blood cells (RBCs) and remain active when the presence of the drug is withdrawn. Fludarabine is the most common drug known to induce drug-independent antibodies. ${ }^{1,4}$

Accepted for publication November 13, 2014. Correspondence: Roby Thomas, MD; robyathomas@gmail.com. Disclosures: The authors have no disclosures. JCSO 2015;13:298-299. (2015 Frontline Medical Communications. DOI 10.12788/ jeso.0160. 
The second type, drug-dependent antibodies, only reacts in the presence of a drug. Here, the antibodies are thought to be triggered by the complex formed between the drug and RBCs. ${ }^{1,4} \mathrm{It}$ is not known which type of antibodies are involved in DIIHA due to nab-paclitaxel.

Another concept is the idea of the "unifying hypothesis." This model is based on animal studies showing no development of antibodies to a small molecule; but when bound to a carrier such as albumin, 3 populations of antibodies could be produced. ${ }^{1}$ One group of antibodies reacted to the chemical, one to the carrier, and one to the complex of both. This theory is relevant to our case since the offending drug is an albumin-bound product, which over time may have generated different types of autoantibodies resulting in a rare case of hemolytic anemia.

As far as we know, anemia resulting from immune hemolysis due to nab-paclitaxel has not yet been reported. This case provides evidence that DIIHA can develop with nab- paclitaxel therapy, even after multiple cycles. It is unclear what the mechanism of this delayed response may be, but it was apparent upon rechallenge that nab-paclitaxel was responsible for inducing acute episodes of hemolysis. Practitioners should be aware that DIIHA with nab-paclitaxel can occur and should become suspicious if patients either experience symptoms during infusion or have a sudden decrease in hemoglobin.

\section{References}

1. Garratty G. Drug-induced immune hemolytic anemia. Hematology Am Soc Hematol Educ Program. 2009;73-79.

2. Garratty G, Arndt PA. An update on drug-induced immune hemolytic anemia. Immunohematology. 2007;23:105-119.

3. Dacha S, Reddivari AK, Latta S, Devidi M, Iroegbu N. Carboplatin induced fatal autoimmune hemolytic anemia: first reported case. World J Oncol. 2010;1:173-175.

4. Garratty G. Immune hemolytic anemia associated with drug therapy. Blood Rev. 2010;24:143-150. 